\title{
Competing for International Materials Leadership... Are Recent Industry Shifts Keeping the U.S. from Fielding Its Strongest Team?
}

\author{
Peter R. Bridenbaugh
}

For the past five years, there has been a seemingly unending flow of resumes across my desk from materials scientists seeking new challenges. While this has been a wonderful opportunity for Alcoa to add talented, experienced scientists and engineers to our laboratories, it has led me to speculate whether many are giving up on the materials business. Such a retreat, if one actually exists, is particularly worrisome because we live at a time where progress on many fronts - aerospace, automotive, chemical processing, defense, biotechnology, electronics - is constrained by materials performance.

Unfortunately the available data are not clear. There is a major decline in $R \& D$ spending in the laboratories of many traditional materials companies, and to a lesser extent, some petroleum companies. But, in general, $R \& D$ spending is increasing.... or, at least, remaining constant... in companies and industries where materials have clearly been identified as barriers to growth and profitability. So, what is happening?

I believe substantial shifts ... in international economics, technology and governmental policies... have been occurring in our industry for several years whose impacts are now just beginning to be fully understood. For most of the decade, the primary metals/ bulk chemicals industries have been very difficult businesses in which to operate profitably in the United States. This oft-repeated story ... globalization, government ownership of primary capacity, commoditization and oversup- ply ... is, by now, quite familiar. A few companies, however, are making progress by recognizing the dramatic improvement in capital productivity that can be realized from a commitment to quality and manufacturing excellence.

Second, the next generation of products have such demanding performance requirements that materials development, product design, and manufacturing processes must all be tightly integrated. These technological realities have redefined the role(s) of the semifabricated product producer.

And finally, the capital intensity of materials production, and the high cost of capital in this country, may be prohibiting many traditional materials companies from actively pursuing new opportunities. This is particularly acute where emerging markets are ill defined and initial volumes small. The costs of entering, or remaining, in the materials industry of the 1990s are clearly going to be high... for many, apparently, too high.

These alterations have forced players in our industry to make one of several choices... leave the commodity business, consolidate operations and abandon product development, or forward integrate toward end-product manufacture.

The results of their decisions around a materials future have clearly influenced investments in $R \& D$ and the movement of scientific and engineering personnel within and without the industry. The most obvious migration of financial, technical and human resources has resulted from the retrenchment of many companies in the materials business. Less apparent... except when accomplished through acquisitions... has been the movement of end-product producers into selective areas of materials development vacated by the traditional materials companies. This particular restructuring of our industry has not received much attention, but will certainly impact the materials marketplace for some time to come.

It should come as no surprise to us that many of our customers are "backward integrating" into materials development. They have realized, as have we, that their long-term growth is in part constrained by materials performance. And, when they looked to their suppliers for solutions, they often found an industry lacking the necessary resources. Furthermore, as final fabricators and systems integrators, they are better positioned to capture the full economic value of materials developments.

The harbinger of this trend, some 25 years ago, was the aggressive pursuit by jet engine producers of superalloy development and their eventual dominance of this field. It was further illustrated very recently by the selection of three airframers and two engine companies to lead the materials development

It is entirely possible... that we are in the midst of a subtle, but profound change in leadership within the materials industry.....

program for the National Aerospace Plane. Thus, it appears certain that the government has come to perceive product manufacturers as the leaders in materials development. Again, this is not particularly surprising because of these companies' preeminence in the development of a broad range of very sophisticated systems, primarily for aerospace and defense. This perception and resulting direction has its merits, but it is also troublesome because it signals, in my opinion, an inappropriate view of the capabilities and roles of materials companies.

It is entirely possible, then, that we are in the midst of a subtle, but profound change in leadership within the materials industry...from the traditional materials companies to the product manufacturers. One could certainly ask, who cares? Is the "location" 
of leadership even important as long as the job gets done? I clearly believe it is! Materials leadership is vital to the global success of American industry. A strong, economically viable and technically astute materials industry represents this nation's best chance to overcome today's complex product and process challenges. And any factors that effectively limit our full participation in this international industrial contest must be viewed with this realization in mind.

Today, we have the ability to measure properties and to study microstructures at levels unheard of 10 years ago. Numerically intense computing has enabled the modeling and display of phenomena we could only imagine when this decade began. Together, these scientific and computing advancements have forever changed the nature of materials R\&D by giving us the capability to understand materials behavior as never before. But who is best qualified to fully leverage this knowledge... the materials company or the product manufacturer?

There is, of course, no single answer to this question. Perhaps our experience at Alcoa Laboratories can provide some insight. We have found that the application of these "tools" is considerably enhanced when incorporated with our knowledge of materials behavior, gained from a century of research and development. This applies even as we have moved into new materials systems. However, in order to reap the rewards of our materials developments, we have found it necessary to pursue product manufacture. We have expanded our design capabilities, developed new manufacturing processes and integrated both with our materials development expertise. This integration of materials science, design, and manufacturing has allowed us to break new ground in materials performance.

I believe those of us in the materials industry, those who possess these diverse, yet intimately related technical resources, are best suited to effectively harness the forces of today's scientific revolution. This is simply the most efficient use of our knowledge and understanding.

This brings me to the subject on which I would like to close... what can be done to assure the effective integration of our limited technological, financial and human resources to address the critical issues of the materials industry and international economic leadership.

As I have already noted, the costs of creating and implementing new materials and their manufacturing processes can be high, the time frames long and the volumes small. If we are to lead the world in this critical arena, it is imperative that we implement a tax policy that encourages rather than penalizes capital formation and that promotes investments in plants, equipment and $R \& D$. The critical role of our academic institutions in this effort must be fully recognized. The efforts to promote interaction between industry, academic and government laboratories should be expanded.

\section{[l]ntegration of materials science, design, and manufacturing has allowed us to break new ground in materials performance.}

The Department of Defense policies linking independent $R \& D$ reimbursement to government sales also need to be re-examined. Traditional materials companies are at a competitive disadvantage because they have historically not been major government contractors and therefore are placed in the position of using their own earnings, not government-reimbursed funds, to pursue proprietary materials development. This often keeps those best qualified to develop new materials and processes from making their maximum contribution.

Finally, the "authorization and consent clause" in our patent law, which has been perceived by many in recent years as a carte blanche for patent infringement, must be revised to clarify and protect the rights of patent owners.

We must challenge any factor, other than the marketplace itself, that keeps key players from bringing all their resources to the table in what is a highstakes, international competition for materials and manufacturing preeminence. The outcome of this contest will influence nothing less than the standard of living of the United States.

Peter $R$. Bridenbaugh is vice president of research and development, Aluminum Company of America, Pittsburgh, Pennsylvania.

\section{THE HOWARD SUPERCONDUCTIVITY INDEX}

\section{All major researchers, institutions, and companies worldwide, separately indexed.}

Available in printed or disk format:

Microsoft File@ for Macintosh $\circledast$ or dBase III@ for IBM $\circledast$ compatible machines.

Printed at $\$ 125$ each Disk at $\$ 225$ each

Order Now From:

Howard Associates

156 Mountain Avenue

Summit, New Jersey, 07901, USA

(201) 277-4312

\section{Payment by check or American Express}

Microsoft File®, Macintosh $($, dBase III $($ and IBM $(8$ are trademarks or registered trademarks of the Microsoft Corp., Apple Computer Inc., Ashton Tate Inc. and International Business Machines Corp., respectively. 